\title{
Prioritization and selection of parameters for control chart implementation based on technical criticality and cost criticality
}

\author{
Sirintra Tan-intara-art and Napassavong Rojanarowan*
}

${ }^{a}$ Department of Industrial Engineering, Faculty of Engineering, Chulalongkorn University, Bangkok, Thailand, 10330

\begin{tabular}{l}
\hline C H R O N I C L E \\
\hline Article history: \\
Received March 2, 2012 \\
Received in Revised Format \\
March 18, 2013 \\
Accepted March 20, 2013 \\
Available online \\
April 1 2013 \\
\hline Keywords: \\
Control charts \\
Statistical process control \\
Parameter prioritization \\
Parameter selection \\
Cost of quality \\
Failure costs
\end{tabular}
\section{A B S T R A C T}
An important problem in control chart implementation is the availability of resources to collect and analyze data for control charts implementation. This paper proposes a method to prioritize and select final product parameters to control. The prioritization is based on cost of quality and technical criticality of those parameters. The prioritization method is demonstrated by a case study of flexible printed circuit manufacturing.

\section{Introduction}

An important performance of manufacturing processes is stability and it is essential to have a quality characteristic or a parameter of a process, which is stable in terms of mean and variation. Sometimes a quality characteristic is described as attribute type, which is associated with visual inspection of defect items such as dent and open circuit. It is also expected to have a stable level of defective rate or defect rate and control charts are useful tools for monitoring any possible change in the process. Control charts have been widely accepted as some of the most necessary and effective statistical tools for process monitoring and improvement. They also help us indicate that the process variation is higher than its natural level when a process goes beyond the control limits. Thus, practitioners can determine when to adjust the process before it causes substantial failure expenditures such as the cost of scrap and the cost of rework (Stuart et al., 1996; Does et al., 1997; Kang et al., 1999; Antony \& Taner, 2003; Bamford \& Greatbanks, 2005; Wang \& Zhang, 2008; Joekes \& Barbosa, 2013).

* Corresponding author. Tel: +66-2218-6828

E-mail addresses: napassavong.o@chula.ac.th (N. Rojanarowan)

(c) 2013 Growing Science Ltd. All rights reserved. doi: 10.5267/j.dsl.2013.04.001 
Schippers (1998) presented some significant factors for the success of statistical process control including the process knowledge, the level of control and the number of products. Virtually, there are several problems associated with the implementation of control charts. These problems are (1) failure in interpretation of patterns found on control charts, (2) lack of knowledge about products and processes, which could cause ineffective corrective action, (3) lack of focus on resources spent on data collection and analysis of control charts (Antony \& Taner, 2003). Many factories have spent significant amount of resources on collecting data associated with different parameters in all production processes. However, they have not paid enough attention to analyze those data in realtime to spontaneously inform the status of the process. Thus, control charts are mis-used as off-line report to customers and do not actually online control the processes (Vommi \& Seetala, 2007).

In the case study factory, where flexible printed circuit boards are manufactured, there exist several problems in implementing control charts. For instance, it is not clear which processes, parameters, and products should be controlled with control charts. Currently, controlled processes, parameters, and products are chosen based on customer requirements. However, the issue arises when there are some parameters that are not requested by customers but they cause significant failure costs such as the cost of re-screening, the cost of rework, the cost of scrap, and the cost of out-of-target in the factory. Thus, these parameters should also be monitored and controlled. However, currently the case study factory does not have a clear guideline on how to determine which parameters should be controlled by the control charts. Therefore, it is important to prioritize the relative importance of parameters to control in order to spend limited resources on those parameters effectively and make sure that both customer satisfaction and failure costs of the company are considered.

\section{Previous work related to parameters prioritization}

According to the IPC Standard 9191 (1999), parameters in manufacturing processes can be classified into three types as follows,

(1) Final Product Parameters (FPPs) are quality characteristics that describe the ability of a product to serve the needs of the customer.

(2) In-Process Product Parameters (IPPs) are quality characteristics of products or parts during the process or the transformation.

(3) Process Parameters (PPs) are factors involved in the process, which affect IPPs or FPPs.

There are a few researches associated with the prioritization of final product parameters for control chart implementation. Ribeiro et al. (2001) proposed the use of quality function deployment (QFD) for determining and prioritizing parameters and processes to control. Xie et al. (1995), and Goh et al. (1998) proposed the prioritization method using quality function deployment (QFD) and analytic hierarchy process (AHP) by considering two criteria: technical criticality and statistical criticality.

The technical criticality of a parameter is considered based on the function importance, the reliability and maintainability importance, and the customer preference importance of that parameter. The statistical criticality is considered based on the process stability and process capability. Rojanarowan \& Jirasettapong (2012) proposed that statistical criticality can be quantified by a 5-scale rating based on the Z-score, or sigma level, or proportion of defectives of each parameter, while technical criticality can be classified by a 5-scale rating from low to high levels. The parameters that have higher sum of both scores should have higher priority. Technical criticality is an important criterion to consider since it directly influences customer satisfaction. Regarding statistical criticality, prioritizing importance of parameters based on the proportion of defectives or process capability indices does not necessarily indicate that parameter which has higher proportion of defectives is more important parameter to control. This is because some parameters with higher proportion of defectives may cause insignificant failure costs to the company, while some parameters with lower proportion of 
defectives may cause significant failure costs and need more attention to control. Thus, this research proposes that failure costs associated with each parameter should be an important criterion to be considered when prioritizing parameters.

\section{Proposed criteria for prioritizing final product parameters for control chart implementation}

This research proposes two methods for prioritizing parameters to control based on two criteria, which are technical criticality and cost criticality subject to some limited resources, which significantly affect customer satisfaction and failure costs of the company.

\subsection{Technical Criticality}

The technical criticality of a final product parameter is considered based on its function importance, the reliability and maintainability importance, and the customer preference importance. The level of technical criticality of a final product parameter can be classified into various levels. This research proposes a common classification of technical criticality levels, which are critical level, major level, and minor level. These levels are widely used for product inspection purpose and for determining types of corrective action to be taken if defectives of that level of technical criticality are found. The definition of each technical criticality is described as follows,

(1) Critical level means the defect type that causes product unfit for use and extreme customer dissatisfaction.

(2) Major level means the defect type that causes major loss if the product is used.

(3) Minor level means the defect type that causes minor appearance nuisance and minor performance loss.

\subsection{Cost Criticality}

This research proposes that cost criticality should be used for prioritization instead of statistical criticality. Statistical criticality is based on the proportion of defectives due to each defect type or each final product parameter. However, the defect type with higher proportion of defectives may not cause higher failure cost since they may have lower failure cost per unit. This research classifies failure costs based on the cost of quality concept (Omachonu et al., 2004). There are four elements of failure costs that are proposed to be considered.

\section{Notations:}

$C_{R S} \quad$ Cost of re-screening per time period

$T_{R S} \quad$ Time spent for re-screening during the time period

$N_{R S} \quad$ Number of operators performing re-screening activity

$W_{R S} \quad$ Wage of re-screening operators

$C_{R W} \quad$ Cost of rework per time period

$T_{R W} \quad$ Time spent for rework during the time period

$N_{R W} \quad$ Number of operators performing rework activity

$W_{R W} \quad$ Wage of reworking operators

$C_{S C} \quad$ Cost of scrap per time period

$N_{S C} \quad$ Number of scrapped pieces per time period

$P_{C U} \quad$ Production cost per unit

$\mu \quad$ Process mean

$T \quad$ Process Target

$M \quad$ Material cost per unit

$N \quad$ Number of units produced during the time period 
(1) Cost of re-screening

This cost occurs when customers return the product lots, which are defectives. The producer is then required by the customers to re-screen the returned lot and re-screen the new lots before sending them out to the customers. The cost of re-screening per period can be calculated as follows,

$C_{R S}=T_{R S} \times N_{R S} \times W_{R S}$.

(2) Cost of rework

The cost of rework occurs when defective pieces can be reworked and it is different depending on the time spent on reworking, which can be specified as follows,

$C_{R W}=T_{R W} \times N_{R W} \times W_{R W}$.

(3) Cost of scrap

Some defect types cannot be reworked and once they occur, the defective pieces must be scrapped. Thus, the company will waste the cost of production of those already produced pieces. The cost of scrap per period can be calculated as follows,

$C_{S C}=N_{S C} \times P_{C U}$.

(4) Cost of out-of-target

For variable parameters, e.g. the thickness of gold coated in gold plating process, there is a target thickness. If the production is not controlled, effectively, the thickness of the coat of some pieces will be thicker than the target value. This causes unnecessary material cost of the product. Thus, the parameter with high cost of out-of-target should be given priority to be monitored by the control chart. The cost of out-of-target per time period can be calculated as follows,

$C_{O T}=(\mu-T) M N$.

\section{Proposed method for prioritizing final product parameters for control chart implementation based on technical criticality and cost criticality}

The proposed method for prioritizing final product parameters for control chart implementation consists of the following three steps,

\section{Step 1: Determine the technical criticality of each final product parameter}

The company classifies the technical criticality level of each final product parameter. The practitioners can use the proposed levels of technical criticality presented in section 3.1 or they can use their own classification.

\section{Step 2: Quantify the failure costs of each final product parameter}

The next step is to quantify the four types of failure costs of each parameter as presented in section 3.2

\section{Step 3: Prioritize and select the final product parameters to control}

This research proposes two methods of prioritization.

\section{Method 1: Focus first on cost criticality}

It is proposed that the controlled parameters are the ones that account for $80 \%$ of total failure costs. The concept comes from Pareto's principle that there are few factors blamed for most of problems (Fotopoulos et al., 2011). In addition, the parameters that have critical level of technical criticality should also be included in the control even though they do not account for $80 \%$ of total failure costs. The reason is that parameter, which has a critical level of technical criticality, significantly influences 
the function of product and the customer satisfaction. Thus, it is necessary that the parameters that have critical level of technical criticality should be monitored by the producer online using control charts in order to detect problem before it reaches the customers. Fig. 1 shows the selection method according to method 1.

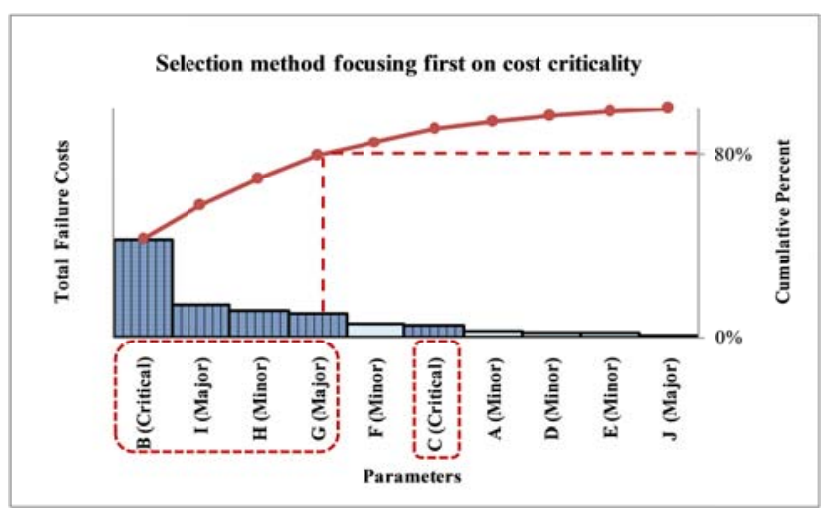

Fig. 1. Selection method focusing first on cost criticality

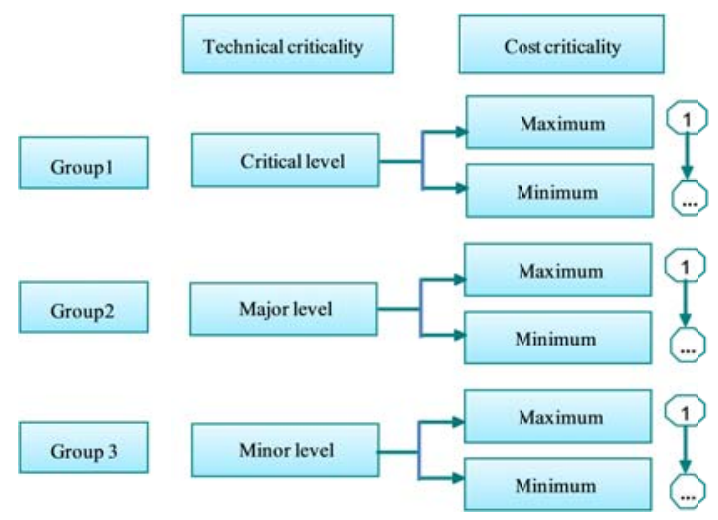

Fig. 2. Selection method focusing first on technical criticality

\section{Method 2: Focus first on technical criticality}

This method proposes that the priority should be given for controlling parameters that have a critical level of technical criticality, followed by parameters that have a major level of technical criticality, and a minor criticality respectively. Within each level of technical criticality, parameters are prioritized based on the amount of failure costs. The selection of the number of parameters to control depends on available resources. This selection method is shown in Fig. 2. This prioritization method guarantees that parameters with higher level of technical criticality are controlled before the lower level ones. This method focuses on controlling parameters that customers pay more attention. However, this method has limitation in case there are various parameters. It is possible that parameters that have higher failure costs may not be controlled since they have lower levels of technical criticality such as minor technical criticality. This research proposes that method 1 of selection should be used since this method guarantees that the parameters that account for significant portion of company's failure costs are controlled. Moreover, this method guarantees that all parameters that critically affect customer satisfaction are also selected to be controlled.

\section{An application of the proposed method}

The case study factory has 51 final product parameters denoted as D1-D51. Most of them are defect types which are attribute parameters such as dent, open circuit, and nick circuit. Only two of them are variable parameters, which are the thickness of coated gold and the circuit size. The selection of final product parameters to control is demonstrated as follows.

\section{Step 1: Determine the technical criticality of each final product parameter}

The company classifies each defect type according to its technical criticality shown in Table 1 .

\section{Table 1}

Classification of technical criticality levels of final product parameters

\begin{tabular}{ccl}
\hline $\begin{array}{c}\text { Level of Technical } \\
\text { Criticality }\end{array}$ & $\begin{array}{c}\text { Number of } \\
\text { Parameters }\end{array}$ & \multicolumn{1}{c}{ Defect Type } \\
\hline Critical & 5 & D1, D2, D8, D30, D40 \\
Major & 30 & $\begin{array}{l}\text { D3, D4, D5, D6, D9, D10, D11, D13, D14, D15, D16, D17, D19, D20, D21, D24, } \\
\text { D25, D26, D27, D28, D29, D31, D38, D41, D42, D43, D46, D47, D48, D49 }\end{array}$ \\
& & D7, D12, D18, D22, D23, D32, D33, D34, D35, D36, D37, D39, D44, D45, D50, D51 \\
\hline
\end{tabular}




\section{Step 2: Quantify the failure costs of each final product parameter}

The next step is to quantify the four types of failure costs of each parameter that are cost of scrap, cost of re-screening, cost of rework, and cost of out-of-target. Table 2 shows the failure costs collected from January to August of 2011 in Thai baht of each final product parameter.

Table 2

Failure costs of final product parameters

\begin{tabular}{|c|c|c|c|c|c|}
\hline Defect type & Scrap cost & Re-screening cost & Rework cost & Out-of-target cost & Total cost \\
\hline D1 & 98,469 & 425 & 0 & 0 & 98,894 \\
\hline D2 & 68,889 & 1,174 & 0 & 0 & 70,063 \\
\hline D3 & 66,249 & 0 & 0 & 0 & 66,249 \\
\hline D4 & 25,294 & 0 & 0 & 0 & 25,294 \\
\hline D5 & 6,478 & 0 & 0 & 0 & 6,478 \\
\hline D6 & 4,688 & 64 & 0 & 0 & 4,752 \\
\hline D7 & 16,455 & 4,560 & 0 & 0 & 21,015 \\
\hline D8 & 16,350 & 4,246 & 0 & 0 & 20,597 \\
\hline D9 & 35,003 & 3,758 & 0 & 0 & 38,761 \\
\hline D10 & 4,905 & 0 & 0 & 0 & 4,905 \\
\hline D11 & 7,068 & 69 & 0 & 0 & 7,137 \\
\hline D12 & 12,132 & 0 & 0 & 0 & 12,132 \\
\hline D13 & 12,405 & 1,004 & 0 & 0 & 13,409 \\
\hline D14 & 39,299 & 490 & 0 & 0 & 39,789 \\
\hline D15 & 9,984 & 1,498 & 0 & 0 & 11,482 \\
\hline D16 & 9,077 & 0 & 0 & 0 & 9,077 \\
\hline D17 & 3,073 & 0 & 0 & 0 & 3,073 \\
\hline D18 & 1,205 & 603 & 0 & 0 & 1,807 \\
\hline D19 & 45,828 & 1,210 & 0 & 0 & 47,038 \\
\hline D20 & 240 & 0 & 0 & 0 & 240 \\
\hline D21 & 641 & 1,861 & 0 & 0 & 2,502 \\
\hline D22 & 51,629 & 0 & 1,210 & 0 & 52,839 \\
\hline D23 & 41,597 & 83 & 1,815 & 0 & 43,495 \\
\hline D24 & 117 & 124 & 0 & 0 & 241 \\
\hline D25 & 8 & 0 & 0 & 0 & 8 \\
\hline D26 & 5 & 0 & 0 & 0 & 5 \\
\hline $\mathrm{D} 27$ & 2,347 & 4,528 & 0 & 0 & 6,875 \\
\hline D28 & 39668 & 0 & 0 & 0 & 39,668 \\
\hline D29 & 61 & 1,171 & 0 & 0 & 1,232 \\
\hline D30 & 3,349 & 0 & 0 & $2,024,207$ & $2,027,566$ \\
\hline D31 & 32,764 & 1,708 & 0 & 0 & 34,472 \\
\hline D32 & 19,822 & 0 & 0 & 0 & 19,822 \\
\hline D33 & 360 & 0 & 0 & 0 & 360 \\
\hline D34 & 9,685 & 2,558 & 0 & 0 & 12,243 \\
\hline D35 & 11,243 & 7,838 & 0 & 0 & 19,080 \\
\hline D36 & 73,262 & 0 & 0 & 0 & 73,262 \\
\hline D37 & 18,594 & 0 & 0 & 0 & 18,594 \\
\hline D38 & 1,942 & 0 & 0 & 0 & 1,942 \\
\hline D39 & 7,638 & 0 & 0 & 0 & 7,638 \\
\hline D40 & 388,927 & 22,396 & 0 & 0 & 411,323 \\
\hline D41 & 10,115 & 14 & 0 & 0 & 10,129 \\
\hline D42 & 20,444 & 701 & 0 & 0 & 21,146 \\
\hline D43 & 4,149 & 1,955 & 0 & 0 & 6,104 \\
\hline D44 & 35,474 & 7,628 & 0 & 0 & 43,102 \\
\hline D45 & 2,476 & 408 & 0 & 0 & 2,884 \\
\hline D46 & 4,699 & 2,218 & 0 & 0 & 6,917 \\
\hline D47 & 425 & 1,969 & 0 & 0 & 2,394 \\
\hline D48 & 10 & $\begin{array}{c}1,50 J \\
0\end{array}$ & 0 & 0 & 10 \\
\hline D49 & 1,660 & 0 & 0 & 0 & 1,660 \\
\hline D50 & 3,926 & 0 & 0 & 0 & 3,926 \\
\hline D51 & 1,647 & 0 & 0 & 0 & 1,647 \\
\hline
\end{tabular}

\section{Step 3: Prioritize and select the final product parameters to control}

This research demonstrates the selection of final product parameters to control based on the selected method of focusing first on cost criticality (method 1). According to this selection method, it is 
proposed that the controlled parameters are the ones that account for $80 \%$ of total failure costs. In addition, the parameters that have critical level of technical criticality should also be included in the control even though they do not account for $80 \%$ of total failure costs. For example, parameters can be prioritized based on their total failure costs using Pareto chart as shown in Fig. 3.

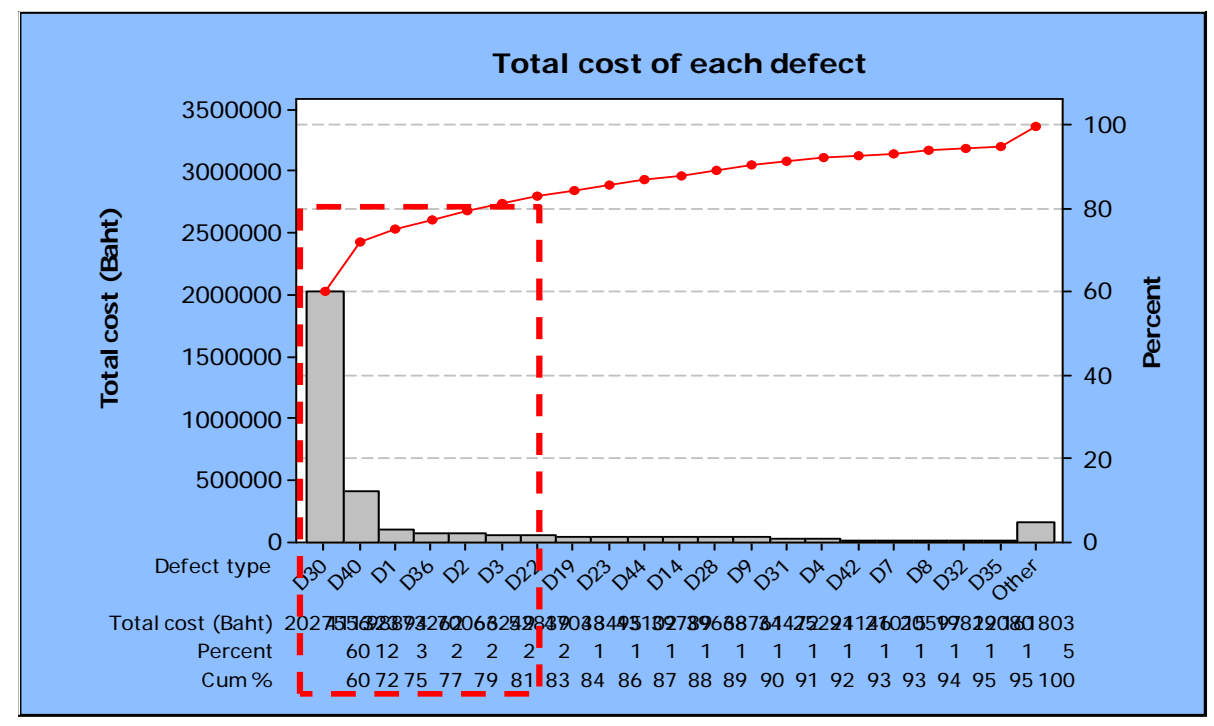

Fig. 3. Prioritized final product parameters based on total failure costs

It can be seen from Fig. 3 that there are six types of parameters that account for $80 \%$ of total failure costs. They are D30 (Plate thickness out of specification), D40 (Blanking mis-position), D1 (Open circuit), D36 (Dent), D2 (Short circuit), and D3 (Nick). Parameters D30, D40, D1, and D2 have critical level of technical criticality, while D3 is in major level and D36 is in minor level. Parameter D8 (Circuit size out of specification) is not in $80 \%$ portion of total failure costs, which means it does not cause significant failure cost. However, this parameter has critical level of technical criticality, which means that this parameter is very important to customers. Therefore, this parameter is also selected to be controlled. Thus, there are a total of seven out of 51 parameters that should be controlled.

\section{Discussion and conclusion}

This research has proposed a method for prioritization of final product parameters to control using control charts. Technical criticality and cost criticality are criteria proposed to be considered. Failure costs are used to determine cost criticality. Main failure costs occurred in practice are cost of scrap, cost of re-screening, cost of rework, and cost of out-of-target. It is proposed that parameters that account for $80 \%$ of total failure costs should be controlled. Moreover, parameters that do not account for $80 \%$ of total failure costs but have critical level of technical criticality should also be controlled.

In practice it is not necessary to control all parameters that account for $80 \%$ of total failure costs. The number of parameters to control at a time depends on the availability of resources used in control. The management should plan for resources necessary for controlling activities.

\section{References}

Antony, J., \& Taner, T. (2003). A conceptual framework for the effective implementation of statistical process control. Business Process Management Journal, 9, 473-489. 
Bamford, D.R., \& Greatbanks, R.W. (2005). The use of quality management tools and techniques: A study of application in everyday situations. International Journal of Quality \& Reliability Management, 22, 376-392.

Does, R.J.M.M., Schippers, W.A.J., \& Trip, A. (1997). A framework for implementation of statistical process control. International Journal of Quality Science, 2, 181-198.

Fotopoulos, C., Kafetzopoulos, D., \& Gotzamani, K. (2011). Critical factors for effective implementation of the HACCP system: A Pareto analysis. British Food Journal, 113, 578- 597.

Goh, T.N., Xie, M., \& Xie, W. (1998). Prioritizing processes in initial implementation of statistical process control. IEEE Transactions on Engineering Management, 45, 66-72.

IPC Standard 9191. (1999). General guidelines for implementation of statistical process control (SPC).

Joekes, S., \& Barbosa, E.P. (2013). An improved attribute control chart for monitoring nonconforming proportion in high quality processes. Control Engineering Practice, 21, 407- 412.

Kang, B.S., Choe, D.H., \& Park, S.C. (1999). Intelligent process control in manufacturing industry with sequential processes. International Journal of Production Economics, 60-61, 583-590.

Omachonu, V.K., Suthummanon, S., \& Einspruch, N.G. (2004). The relationship between quality and quality cost for a manufacturing company. International Journal of Quality \& Reliability Management, 21, 277-290.

Ribeiro, J.L.D., Caten, C.S. \& Fritsch, C. (2001). Integrated process control. International Journal of Quality \& Reliability Management, 18, 444-464.

Rojanarowan, N., \& Jirasettapong, P. (2012). Prioritizing processes and selecting parameters for control charts implementation. Advanced Science Letters, 14, 310-315.

Schippers, W.A.J. (1998). Applicability of statistical process control techniques. International Journal of Production Economics, 56-57, 525-535.

Stuart, M., Mullins, E., \& Drew, E. (1996). Statistical quality control and improvement. European Journal of Operational Research, 88, 203-214.

Vommi, V.B., \& Seetala, M.S.N. (2007). A new approach to robust economic design of control charts. Applied Soft Computing, 7, 211-228.

Wang, W., \& Zhang, W. (2008). Early defect identification: application of statistical process control methods. Journal of Quality in Maintenance Engineering, 14, 225-236.

Xie, M., Goh, T.N. \& Xie, W. (1995). Prioritizing processes for better implementation of statistical process control techniques. IEEE Annual International, 260-263. 